\title{
THEORETICAL-METHODOLOGICAL BASIS FOR THE ASSESSMENT OF WORK MOTIVATION IN HOSPITAL IN BULGARIA
}

\author{
D. Mitev* \\ PhD Student, Faculty of Public Health, Medical University, Sofia, Bulgaria
}

\begin{abstract}
The report notes that in today's dynamic conditions the increase in the work motivation of hospital staff has a direct positive effect on the efficiency and the results of their work. The aim of the report is to present the methodological approaches and tools for analyzing and evaluating the work motivation in hospital care. On this basis,is developed a methodological framework for its research, and is also specified which method at which stage of the studyt is appropriate to be implemented.
\end{abstract}

Key words: work motivation, hospital care institutions, methodological framework

\section{INTRODUCTION}

Motivation is an old and not yet fully explored organizational problem, strongly influencing the results of labor behavior. The difficulty in defining what motivates human behavior in the work process is based, on the one hand, on the diversity of motivational factors leading to the desired labor outcome and, on the other hand, on the difficulty of explaining the essence of the human psyche. The specificity of the system and the specificities of work in this field imply a separate model for analysis of labor motivation in healthcare. The aim of the paper is to present the methodological approaches and tools for analyzing and evaluating the work motivation in hospital care. On this basis, the methodological framework for its research is being developed and is specified which method at which stage of the study is appropriate to be applied.

\section{METHODOLOGICAL APPROACH} AND TOOLKIT FOR THE STUDY OF LABOR MOTIVATION IN HOSPITAL CARE

There is no uniform definition of labor

\footnotetext{
*Correspondence to: Dimitar Mitev, PhD Student, Faculty of Public Health, Medical University, Sofia, Address: Sofia, Faculty of Public Health, Medical University, Sofia, tel: 0888 869620, email:albenakm@yahoo.com
}

motivation in the healthcare sector, but a vast range of methods can be used to study the state of the work motivation system applied in hospital care with a view to acquiring information on the subject from more points of view in order to obtain maximum objectivity. The proposed methodical approach is based on information - collected through a literature review, in-depth interviews and interviews with representatives of the investigated medical establishments as well as own expertise.

It is advisable to use methods that allow to obtain a complex assessment and provide opportunities for comparing the actual state of the work motivation system with the desired optimal effective state.

The Case Study method uses the gained previous experience as a starting point. It allows us to learn from actual situations in the past and from actual consequences. The method develops skills to work with data, to link facts with actions, to decide what should be done, and to engage with a direction of development, i.e. sequence in the workflow. Irrespective of the trends of concrete studies in which this method is applied, it concerns the consideration and analysis of a one particular case, with the possibility of (but not necessarily) involving more than one case 
study. This method does not have a strict framework and constraints for the application of specific methods and procedures, and it is not necessary to process the collected data through complex statistical procedures $(2,3$, 9).

This method, predominantly used in social sciences, offers us a systematic approach to phenomenon monitoring, data collection, information analysis and results. The main purpose of a case-by-case study is to obtain more diverse information about different aspects, features, views from different points of view, on the basis of which a more comprehensive description and assessment can be made and the analysis is enriched.

This method of empirical research allows the study of a phenomenon in its natural environment, which makes it extremely useful for the study of the work motivation in certain medical establishments and the directions for its improvement to be transferred to other medical institutions working in similar conditions.

In the context of the conducted study, the information about certain attitudes of the end users (individual level) regarding the applied system of labor motivation is beneficial. These are qualitative data and indicators, for which the survey method is very appropriate.

Questionnaires should allow the following key research questions to be answered:

1. The extent to which systems of labor motivation or part of it operate in the analyzed medical establishments and to what degree the system (main activities and procedures regulated by internal documents) have been developed;

2. What is the opinion of the medical staff about the effective functioning of the system?

3 . Which are the problem areas that should be optimized.

In addition to the surveys, it is also appropriate to use in-depth interviews. This is another widely used quality method for collecting quality (less often quantitative) data when conducting consumer surveys. They are applied successfully in a variety of situations and are particularly suited to questions whose answers might deviate from any accepted norms. This could also be the question of the satisfaction of the system of labor motivation the assumption may lead the anonymous poll users to not present properly their own attitude to this issue. At the same time, personal depth interviews could identify the real impact of the studied motivation factors.

The documentary method allows to make a review, to analyze legislative documents and literary sources concerning health motivation, internal acts of medical establishments, research papers related to specific activities in the system (motivational profiles) and other.

The motivation profiles method serves to develop motivational profiles of the examined categories of medical staff, showing the degree of satisfaction and dissatisfaction with their work. The motivation profile itself can be considered according to Yosif Iliev as "... the motivation profile represents a complete, complex picture of the level of satisfaction of the staff (or the workers of the group) according to the impact of the main motivational factors". Sava Djnev and Plamen Dimitrov define that "Motivation profile gives the portrait of the personality in terms of what and how motivates him in the organization. The motivation profile is an analytical illustration of the extent to which the company meets the different needs of its employees. In this sense, the motivation profile depends both on the needs, values and interests of employees, and on the availability of the organization to meet their needs. "(1).

M. Kuzmanova postulated that "The study of the motivational profile of the organization makes it possible to identify the main inconsistencies between the employees' ideas, desires and expectations of the motivational impact and the factually realized impact. The analysis is a means of enhancing the effectiveness of motivation through sound managerial impact. "(7). The main conclusion that can be drawn from the three definitions is that staff satisfaction is directly related to motivation. The technology of building a motivational profile involves at least two lines of assessment of the factors of the work situation. One is by degree of significance and the other one by level of satisfaction. As a rule, for each factor of labor motivation the two assessments are compared and this comparison is the basis for describing, explaining, forecasting the specific work situation in a given establishment for a certain category of staff.

Statistical software and statistical and mathematical methods are used to analyze the 
obtained information as it enables the data to be successfully, quickly and efficiently summarized, systematized and processed, all the necessary calculations and transformations can be made in real-time, with the ultimate goal to define conclusion that would, with a high probability of assurance, also be applied to the whole.

The overview and evaluation of the approaches and methods of labor motivation study give us the reason to conclude that they are suitable for the analysis and assessment of its condition in the health sector.

\section{METHODOLOGICAL FRAMEWORK FOR THE STUDY OF THE SYSTEM OF WORK MOTIVATION IN HOSPITAL CARE}

The motivation of human resources is a complex, difficult-to-solve issue due to the disparity of human individualities, temperamental differences, different values system, the different roles played by the categories of staff. What an employee considers important and motivates him to perform certain actions for another employee is totally useless. There are also differences in the perceptions of what prize motivates people to do well. People differ in how they judge a particular action and how much it fits into the idea of gaining a success with an action. In order to evaluate and explore labor motivation, it is necessary to identify the needs of the employees, the motivation factors that motivate them and on this basis to solve the issues of improving the motivational climate.

The aim of the methodological framework is to create and identify appropriate tools for diagnostic analysis and assessment of the state of work motivation in the healthcare establishments. This will allow the problems to be uncovered and to take action to remove them. For this purpose, based on the methodology of Prof. Y. Iliev (4) for developing motivational profiles, we will study and evaluate the state of work motivation in selected health establishments. It will be investigated through the inquiry method the motivation environment in the selected medical institutions. Through in-depth interviews, is examined how corporate motivation coincides with the individual. Methodological issues and motivational factors are interpreted and adapted according to the specifics of the work done in the medical institutions. (8)
The first stage determines the type of the survey and the nature of the in-depth interview, as well as the selection of the specific objects.

The study is complex. On the basis of the method "case study" the concrete investigated medical establishments are defined. According to the specifics of the health care establishments and the labor input there is applied the requirement that the use of statistical methods, which determines the number of staff, the number of employees to be interviewed, is not required. It is assumed that the number of respondents from the hospital is between $50 \%$ and $100 \%$. (6). As the physicians and health care professionals are the most important to achieve high quality healthcare services, the study targets these two categories of staff. The logical unit of the survey is the surveyed physicians and healthcare professionals.

The study is targeted at a selected range of health care establishments, with the aim of deepening and completing the motivational factors and the specific causes of existing problems. This will allow to be drawn recommendations as guidelines for management to take urgent measures and actions to overcome ineffective work motivation and the factors that determine it.

One of the components includes the study and analysis of the specificity of the existing system of work motivation for medical professionals / doctors and healthcare professionals /, the level of motivation and the factors that affect them - are encompassed doctors and health care professionals working in the selected medical establishments. The appropriate motivational factors are formulated, which allows the development of a motivational profile of the medical establishment as well as of the different categories of staff. On this basis are disclosed the attitude of the staff to their work, their loyalty, the risk of quitting, the nature of the relations between the different categories of staff, the reserves for building an effective system of work motivation to improve the quality of the medical service and results in the work of the hospital.

For the purposes of this study, we consider it appropriate to conduct the analysis in hospitals for two main categories of medical staff, and the analysis ends with the creation of individual motivation profiles. This approach will allow a fuller disclosure of the degree of motivation of the working medical staff and, 
on this basis are provided directions for improving the motivational climate.

Therefore, it is important to identify the factors that are the reason for improving the work motivation of healthcare professionals. The motivation status of different employees employed in an enterprise (different from a point of view of position, education, age, gender) is determined by two sets of factors. One is valid for all employees and the other has a personal validity for each individual and is associated with the individual's personal motivation. Motivating factors become so only when they are optimized, ie. it is necessary to assess their condition.

Such motivating factors are the level of wages, which should be preferably higher than the average in the sector. Achieving high official status; good interpersonal relationships with colleagues and superiors; ensuring healthy and safe working conditions; a high level of workplace security; valid for all equal working rules; adequate, fair assessment and recognition of labor competence and the specific contributions of each employee; ensuring clear career development conditions; challenging and creative work; loyalty, sense of belonging and commitment to the medical establishment; good social benefits such as sports cards, food vouchers, additional medical insurance are common motivating factors.

It is advisable to take into account the cultural and educational status of the respondents in the development of the questionnaire. Physicians and health care professionals have a high educational and cultural level, which implies the possibility of obtaining accurate answers. 15-20 motivational factors are selected, related to the specifics of the respondents' work in order to compile the anonymous questionnaire. These factors are necessarily discussed with elected representatives of the medical establishment (eg. nurse and head of wards). The following factors have been selected to cover the issues of external and internal motivation:

1. Level of pay / above average for the sector and clearly defined criteria for allocating additional material incentives /

2. Social benefits provided by the health care institution / additional medical insurance, food vouchers, sports cards/

3. Opportunity for growth, career /based on real achievements and personal merit, on an adequate assessment /

4. Job satisfaction / interest is interesting and stimulates creative possibilities/

5. Opportunity for training and upgrading of qualifications / regular courses, conference visits, etc. /

6. Opportunity to initiate and realize own goals

7. Recognition of abilities and skills /delegation of additional rights and powers, granting the right of self-control, etc./

8. Level of responsibility for the particular worker /whether it corresponds to his / her job description/

9. Workplace security / there is a peace at work, working without stress that it can be lost/

10.Working conditions /healthy and safe environment/

11.Style and behavior of the leadership /democratic leadership is in place, the opinion of all people is respected and they are adequately evaluated for their achievements and commitment to the hospital/

12. Good collegial relations

13. Awareness of the events in the medical establishment /enough channels are provided to obtain timely and accurate information about the events/

14.Improvement of the quality of the clinical activity in the medical establishment /ambiguous forms of material and moral encouragement have been created to improve the outcomes of the health services/

15.Prestige of the profession /an organizational culture has been created to highlight the sense of commitment to the hospital, to create a good image and a high quality of work of the health workers/

Apart from the opinion of the respondents regarding the ranking of the factors of importance, it is important for the purpose of the analysis whether each of the respondents is aware of the influence of the relevant factor: whether he is satisfied with the influence of the factor, whether he is not aware of this influence, or unsatisfied. In order to obtain this important information for the development of the motivation profile in the questionnaire, the respondents' opinion is sought for their degree of satisfaction with each of the factors.

The second part of the survey aims to explore and analyze the personal opinion of the respondents about the nature of the motivation environment in the health care establishments in terms of: working conditions; knowledge of the job and their expectations for work; their 
attitude towards proportionality between remuneration and work; satisfaction with the profession; self-assessment of working behavior; opportunities for training, career development and initiative; relationship with management. The actual part of the questionnaire is focused on the factors that the healthcare institution needs and can manage in order to improve the system of work motivation. It is necessary to establish the origin of the factor - whether it stems from the working environment, the company culture, the management of the enterprise and others. It is important to take into account personal factors such as mood, personality situation /salary increase or other/. Questions need to be grouped, and there may be ranging and assessment of factors.

Labor motivation depends on both organizational and managerial actions as well as on individual personality characteristics and perceptions of the specialist. Therefore, the additional questions start with a question expressing the personal judgment of the interviewee and are related to the results of the work. Their role is to clarify the quantitative measures of labor performance, using open questions that direct the degree to which the specialist is committed to the work he performs.

The questionnaire ends with the classification of the specialist by gender, age, education, experience. The link between the results and the different classification attributes can be traced.

In-depth interviews with a sample of executives in the surveyed establishments will be conducted to investigate the opinion of management staff in medical establishments. The questions aim to clarify and establish the position of managers on key issues for the study of the system of work motivation of doctors and healthcare professionals:

1. What is the state of work motivation of specialists in your medical establishment?

2. What are the main problem areas that aggravate work motivation?

3. Do you have specific action on the study of motivation and on what periods do you conduct the study?

4. Do you have in your enterprise a regulation of core activities in relation to the assessment of performance and the management of the remuneration of doctors and healthcare professionals?
5. Are the specialists familiar with the above regulation and do they perceive its application as fair?

6. Does the enterprise work with an optimized number of specialists?

7. When establishing a low labor motivation for specialists, what specific measures do you use to address the problem?

The second stage is the conduct of the poll itself.

The conduct of the survey is preceded by a briefing explaining to the respondents the purpose of the questionnaire related to improving the motivational climate in the hospital, how the factors motivators affect the overall work and how they can be managed to overcome demotivation of professionals. The survey is not intended to evaluate respondents, it is not related to pay changes or staff release. The purpose of the survey is to reveal the personal positions of the respondents about the weaknesses of the system of labor motivation in the given medical establishment. We need honest and sincere answers to get to the essence of motivational issues. The generalized summaries and recommendations can be used to improve the work environment and overcome the encountered problems. Specialists explain that the survey is anonymous and the given answers will only be used for the purposes of this study. It is highlighted that there are no truel or wrong answers in the questionnaire.

The third stage is processing the survey cards and summarizing the results of the survey, and the fourth stage is developing a motivational profile of the staff in the health care facility.

The last five stage is related to the development of guidelines for improving the system of labor motivation of human resources in the healthcare establishments. The basis of these proposals lies in the ranking of factors by priority, the degree of satisfaction expressed by the respondents, the answers to the additional questionnaire questions and the in-depth interviews.

The considered methodical issues of the analysis of the system of labor motivation in the healthcare establishments give the opportunity to draw out specific directions for improving the motivational climate and improving the motivation of the staff in the medical establishments. 


\section{CONCLUSION}

In the health care institutions in the country, systems of labor motivation are often not applied or they do not take into account the achievements of the Bulgarian practice from other sectors of the economy as well as the good world examples. There are problems with the implementation of individual elements of the system of labor motivation, the possibilities for its improvement and practical realization. These deficiencies obstruct the efficient management and activity of the medical institutions and significantly reduce the positive role of the most important capital of the medical institutions - their staff. In conclusion, it can be summarized that the presented methodological framework of the study gives clarity about the essence of the methods and the measures for research and also shows which method at which stage of the study is applied. The review and assessment of the approaches and methods for studying the motivation of employees give us the reason to conclude that they are applied as a whole for the analysis and evaluation of the state of the system of labor motivation in the healthcare establishments and can help to improve it.

\section{REFERENCES}

1. Jonev, S. and Dimitrov, P., Organizational consulting (vol. 3). Sofia: N G BV Consulting, pp.144, 2015

2. Venelinova, $\mathrm{H}$, The use of method „case study" for study of the interaction, Scientific works of Russe University, Russe, 2013

3. Ivanov, I., Pedagogical diagnostics, University Publishing House „Episkop Konstanting Preslavski“", Shumen, 2006

4. Iliev, Y., Management by motivation, University Publishing House „, Chernorizec Hrabar", Varna, pp. 239-310, 2009

5. Iliev, Y., Personnel motivation, IK,Liuren“, Sofia, pp. 40, 1993

6. Iliev, Y., The ability to motivate, Publishing House "Nova zvezda", S., 2001

7. Kuzmanova, M. And Alexandrova, M., Management theory and practice, Publishing House "Vezni-4", Sofia, pp. 290., 2013

8. Miteva, A., Organizational behavior, RK „Poni“", Sofia, 2006

9. Thomas, G.: A Typology for the Case Study in Social Science, University of Birmingham, 2011 